\title{
Exenatide - A Novel Treatment to Manage Type 2 Diabetes Mellitus
}

\author{
a report by \\ Manel Puig-Domingo, ${ }^{1}$ Alicia Gervás-Ríos, ${ }^{2}$ Cristián Fernández-Fernández ${ }^{1}$ and Jesús Reviriego² \\ 1. Endocrinology, Nutrition and Diabetes Service, Hospital Clínic, Barcelona; 2. Department of Clinical Investigation, Lilly SA, Madrid
}

DOI:10.17925/EE.2007.00.01.23

The epidemic characteristics of type 2 diabetes mellitus (T2DM) pose a challenge to the healthcare resources needed to treat this chronic disease and also to prevent its associated cardiovascular (CV) complications, the number one cause of T2DM-associated morbi-mortality and its social and personal impact. There is currently a growing number of available treatments that make it possible to achieve targeted glycaemic control in most patients, albeit only temporarily in many patients due to the progressive nature of the disease. Current therapies often entail undesirable side effects, such as weight gain or hypoglycaemia, limiting their optimisation. Recently, a new class of drugs has become available for the treatment of T2DM: incretin mimetics. Exenatide is the first incretin mimetic available to date. It acts in a similar way to glucagon-like peptide-1 (GLP-1), an intestinal incretin hormone that is naturally secreted following the intake of nutrients. Unlike GLP-1, which has a halflife too short to make it viable for treatment, exenatide is resistant to degradation by the enzyme dipeptidyl peptidase-4 (DPP-4). Exenatide has shown to increase glucose-dependent insulin secretion, decrease glucose-dependent post-prandial secretion of glucagon, slow gastric emptying and reduce food intake. Furthermore, some of these effects represent mechanisms that have a significant positive impact on glucose homeostasis and a beneficial effect on bodyweight. Clinical trials (phase III triple-blind studies) have shown that exenatide can decrease glycated haemoglobin $\left(\mathrm{HbA}_{1 \mathrm{C}}\right)$ by $1 \%$, together with weight loss and infrequent hypoglycaemic episodes in patients not well controlled with previous metformin and/or sulphonylurea treatment. Nausea is the main side effect when starting treatment with exenatide and can decrease with continued use of exenatide. Moreover, pre-clinical studies in experimental models suggest that exenatide might have a promising effect on pancreatic islet $B$-cell function and mass. Overall, exenatide provides a treatment option for patients with T2DM who have not achieved adequate glycaemic control while on maximum tolerated doses of metformin and/or sulphonylurea therapy.

\section{Background}

T2DM affects more than 150 million people worldwide. ${ }^{1,2}$ The World Health Organization predicts that by 2025 the number of people affected will double, largely due to demographic growth, the ageing population, unhealthy eating, obesity and sedentary lifestyles in most developed countries. ${ }^{2-4}$ T2DM is associated with a series of macro- and micro-vascular complications that lead to disabilities, loss of employment and premature death, resulting in increased utilisation of healthcare resources.

It is widely accepted that the current treatment of T2DM requires a progressive pharmacological approach, as pointed out recently by the American Diabetes Association (ADA) and the European Association for the Study of Diabetes (EASD). ${ }^{5}$ The first step in T2DM treatment is to improve the glycaemic control of patients by implementing lifestyle changes, such as dietary modifications and increased physical activity. Once the first intervention is no longer effective, other drugs such as metformin, sulphonylureas, thiazolidinadiones (TZDs), meglitinides and $\alpha$-glucosidase inhibitors are added to achieve the desired targets. These groups of drugs lower glucose levels by means of different mechanisms of action and can be used in mono- or combination therapy. ${ }^{3}$

The initial and subsequent dose titration may be limited by the emergence of adverse effects. Nevertheless, despite the many treatment options currently available, for many T2DM patients glycaemic control continues to be inadequate.

It is well-known that after a variable period of time of treatment with oral medications (roughly 5-7 years), and given the progressive nature of the illness, B-cell function declines sharply, making insulin necessary in approximately half the cases. ${ }^{6}$

Most existing therapeutic options have been developed without prior definition of molecular targets. The advances being made in understanding the pathogenesis of T2DM provide the opportunity to develop new treatment interventions, ${ }^{7}$ such as using glucose-regulating peptides known as incretins. ${ }^{8}$

\section{Concept and Physiology of the Incretin Effect}

Incretins are hormones that are released into the circulation by gut cells in response to food intake, and exert a significant number of glucose regulating actions including an insulinotropic effect - that is, an increased glucose-dependent secretion of insulin.9,10 These hormones include the glucose-dependent insulinotropic polypeptide (GIP) secreted by intestinal K cells, mainly located in the jejunum, and also throughout the rest of the

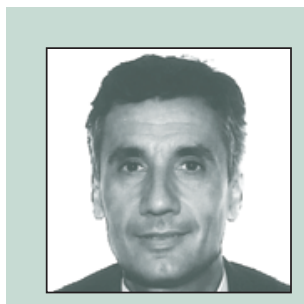

Manel Puig-Domingo is a Consultant in the Endocrinology, Nutrition and Diabetes Service at the Hospital Clinic, Barcelona. His primary research interests include the prevention of type 1 diabetes, the treatment of type 2 diabetes, the endocrinology of ageing and thyroid cancer. Dr Puig-Domingo is Vice-President of both the Catalan Society of Endocrinology and the Spanish Society of Endocrinology. He has authored 68 peer-reviewed papers, 18 reviews and 22 chapters of books. Dr Puig-Domingo obtained his PhD in Endocrinology at the Universidad Autónoma de Barcelona in 1988, and was Associate Professor of Medicine at the same institution from 1991 to 2000. Earlier in his career he spent two years at the University of Texas Health Science Center at San Antonio, from 1986 to 1988, where he was a Research Fellow in the Department of Cellular and Structural Biology and Assistant Professor at their School of Medicine. Prior to this, Dr Puig-Domingo was a Resident in Endocrinology at Hospital de Sant Pau, Barcelona. 
gut, ${ }^{11}$ and GLP-1, secreted by intestinal glucose-responsive neuroendocrine (L) cells, mainly located in the ileum and the colon, and in the duodenum and jejunum. The incretin effect is the phenomenon by which greater insulin secretion results after oral glucose intake than after infusion of comparable amounts of intravenous glucose. ${ }^{12}$

\section{Role of Incretins in Regulating Glucose Homeostasis}

Different studies have consistently demonstrated the glucose-regulating effects of GLP-1. The underlying mechanisms were discovered by administering GLP-1 and GLP-1 antagonists in animal models. These glucose-regulatory effects include glucose-dependent insulinotropic effect, inhibition of glucagon secretion, slowed gastric emptying and cytoprotection of cells (in experimental models). ${ }^{13-20}$

\section{Glucose-dependent Insulinotropic Effect}

The incretin effect of GLP-1 - increasing glucose-dependent insulin secretion - is mediated by the interaction of GLP-1 with its specific receptor bound to a $\mathrm{G}$ protein in $B$ cells that stimulates adenylcyclase and

Unlike most antidiabetic medications, incretin mimetics also suppress postprandial secretion of glucagon, slow gastric emptying and reduce food intake and bodyweight, thus providing a positive scenario for a comprehensive amelioration of metabolic status in type 2 diabetes mellitus patients.

increases the generation of cyclic adenosine-3', 5'-monophosphate (cAMP), which increases intracellular $\mathrm{Ca}++$, ultimately triggering insulin secretion. ${ }^{21-23}$ These actions depend on glucose levels, so that the insulinotropic effects of GLP-1 decrease as plasma concentrations of glucose approach normal values. ${ }^{24}$ Furthermore, GLP-1 has been shown to enhance the first phase of insulin secretion in patients with T2DM, which is generally absent in these patients. ${ }^{25}$

\section{Inhibition of Glucagon Secretion}

GLP-1 suppresses glucagon secretion by pancreatic cells when glucose concentrations are elevated. ${ }^{26}$ This glucagon-static effect of GLP-1 is accompanied by a decrease in hepatic glucose production. There is no consensus as to whether GLP-1 exerts a direct effect on $\alpha$ cells, since it is not known whether $\alpha$ cells express receptors for GLP-1, or whether there is an alternative paracrine regulation by means of somatostatin. ${ }^{27}$

\section{Gastric Emptying Effect}

The rate of gastric emptying is the main regulatory mechanism of the amount of nutrients that reach the small intestine. GLP-1 is one of several factors that modulate the rate of gastric emptying. ${ }^{28}$ It has been postulated that GLP-1 regulation of gastric emptying is mediated by specific receptors in the brain, promoting vagal stimulation. ${ }^{29,30}$

\section{Cytoprotection of $\beta$ Cells}

Studies in vitro and in vivo have demonstrated that GLP-1 increases cell mass and maintains B cell function. The effects of GLP-1 on B cells have been categorised as:

- acute: GLP-1 increases glucose-dependent insulin secretion;

- subacute: GLP-1 stimulates pro-insulin transcription and insulin biosynthesis; and

- chronic: GLP-1 stimulates both the proliferation and neogenesis of B cells from ductal precursor cells and decreases their apoptosis. ${ }^{31-33}$

\section{Limitations of Therapeutic Use}

GLP-1 has been investigated in some short-term clinical trials to explore its therapeutic potential for patients with T2DM. ${ }^{34}$ However, because of the rapid degradation of the molecule by the DPP-4 enzyme, the therapeutic usefulness of GLP-1 is limited by the need for chronic infusion and the temporary nature of its effects once infusion is suspended.

\section{Incretin Mimetics}

Incretin mimetics are molecules that mimic different physiological effects of the incretin GLP-1, such as glucose-dependent insulin secretion in clinical and pre-clinical models. Unlike most antidiabetic medications, incretin mimetics also suppress post-prandial secretion of glucagon, slow gastric emptying and reduce food intake and bodyweight, 35,36 thus providing a positive scenario for a comprehensive amelioration of metabolic status in T2DM patients. Likewise, beneficial actions have been revealed in cell lines and in animal models, such as a promoting B-cell proliferation and neogenesis.

\section{Exenatide}

In 2006, the European Commission approved an exenatide injection called Byetta $^{\mathrm{TM}}$ used for treatment of T2DM in combination with metformin and/or sulphonylureas in patients who have not achieved adequate glycaemic control on maximally tolerated doses of these oral therapies. ${ }^{37}$

\section{Pharmacology}

Exendin-4, a natural peptide containing 39 amino acids, was identified and isolated from the saliva of a lizard commonly known as the gila monster (Heloderma suspectum), native to the Gila river valley in Arizona and New Mexico. Exendin-4 shares several glucoregulatory actions with GLP-1. ${ }^{38,39}$ Exenatide is the synthetic form of exendin-4. Exenatide is not an analogue of the GLP-1 hormone, although it shares $53 \%$ of its amino acid sequence. Unlike GLP-1, exenatide is resistant to the action of DPP-4 due to substitution of glycine for alanine in position 2, and therefore has a longer half-life. ${ }^{40}$

In various pre-clinical studies, exenatide has been shown to exert antidiabetic actions similar to those described for the incretin GLP-1, such as enhancing glucose-dependent insulin secretion, suppressing the concentration of high glucagon levels, slowing gastric emptying, decreasing food intake and inducing neogenesis of pancreatic islets. ${ }^{41-49}$

\section{Pharmacokinetics/Pharmacodynamics}

The pharmacokinetic profile of exenatide has been researched clinically in healthy volunteers ${ }^{50,51}$ and in patients with T2DM. ${ }^{52,53}$ Peak plasma concentrations are reached after 2.1 hours, with similar bioavailability following subcutaneous administration in the abdomen, thigh or upper arm. ${ }^{51}$ Results of pre-clinical studies indicate that the drug is eliminated primarily by glomerular filtration, followed by proteolytic degradation. ${ }^{54,55}$ Exenatide has a half-life of 2.4 hours, and plasma concentrations are 
Exenatide - A Novel Treatment to Manage Type 2 Diabetes Mellitus

Table 1: Efficacy of Exenatide $(5-10 \mu \mathrm{g})$ for AMIGO Clinical Trials

\begin{tabular}{|c|c|c|c|c|c|c|c|c|c|}
\hline \multirow{3}{*}{$\begin{array}{l}\text { Drug } \\
\text { Treatment }\end{array}$} & \multicolumn{3}{|c|}{ AMIGO I } & \multicolumn{3}{|c|}{ AMIGO II } & \multicolumn{3}{|c|}{ AMIGO III } \\
\hline & \multicolumn{3}{|c|}{ Exenatide+metformin } & \multicolumn{3}{|c|}{ Exenatide+sulphonylurea } & \multicolumn{3}{|c|}{ Exenatide+(sulphonylurea+metformin) } \\
\hline & Placebo & $5 \mu \mathrm{g}$ & $10 \mu \mathrm{g}$ & Placebo & $5 \mu g$ & $10 \mu \mathrm{g}$ & Placebo & $5 \mu g$ & $10 \mu g$ \\
\hline Treatment ITT (n) & 113 & 110 & 113 & 123 & 125 & 129 & 247 & 245 & 241 \\
\hline Population evaluated (n) & 89 & 90 & 91 & 73 & 93 & 89 & 184 & 205 & 188 \\
\hline Baseline A1C (\%) & 8.2 & 8.3 & 8.2 & 8.7 & 8.5 & 8.6 & 8.5 & 8.5 & 8.5 \\
\hline Change at week 30 & +0.1 & -0.4 & -0.8 & +0.1 & -0.5 & -0.9 & +0.23 & -0.55 & -0.77 \\
\hline Evaluated (\%) & 13 & 32 & 46 & 9 & 33 & 41 & 9 & 27 & 34 \\
\hline $\operatorname{ITT}(\%)^{*}$ & 11 & 27 & 40 & 8 & 27 & 34 & 7 & 24 & 30 \\
\hline Baseline FPG (mmol/l) & 9.4 & 9.8 & 9.3 & 10.8 & 10 & 9.9 & 10 & 10.1 & 9.9 \\
\hline Change at week 30 & +0.8 & -0.4 & -0.6 & +0.4 & -0.3 & -0.6 & +0.8 & -0.5 & -0.6 \\
\hline Baseline weight (kg) & 100 & 100 & 101 & 99 & 95 & 95 & 99 & 97 & 98 \\
\hline Change at week 30 & -0.3 & -1.6 & -2.8 & -0.6 & -0.9 & -1.6 & -0.9 & -1.6 & -1.6 \\
\hline
\end{tabular}

ITT = intent to treat population; FPG = fasting plasma glucose.

* Numbers have been rounded to the nearest whole value.

detectable up to 10 hours following subcutaneous administration. ${ }^{51,55}$

Other pharmacokinetic studies of exenatide in male and female Caucasian, Hispanic, Japanese and black patients aged 22-73 years have shown that age, sex and race have no significant effects on the pharmacokinetics of subcutaneous administration of exenatide. ${ }^{37,56}$ Furthermore, obesity (body mass index (BMI) $\geq 30 \mathrm{~kg} / \mathrm{m}^{2}$ ) does not appear to modify exenatide's pharmacokinetic profile. ${ }^{55}$ Experience in patients with $\mathrm{BMI} \leq 25$ is limited. ${ }^{37}$

In patients with mild renal impairment (creatinine clearance $50-80 \mathrm{ml} / \mathrm{min}$ ) or moderate renal impairment (creatinine clearance $30-50 \mathrm{ml} / \mathrm{min}$ ), exenatide clearance is slightly decreased compared with clearance in individuals with normal renal function (13\% reduction in mild and $36 \%$ reduction in moderate renal impairment). No dosage adjustment is required in these cases, but in patients with moderate renal impairment, dosage escalation from 5 to $10 \mu \mathrm{g}$ should proceed conservatively. ${ }^{37,57}$ In patients with severe renal dysfunction treated with dialysis (creatinine clearance $<30 \mathrm{ml} / \mathrm{min}$ ), the clearance of exenatide is reduced by more than 10 -fold $(0.91 / \mathrm{h}$ compared with $9.1 \mathrm{l} / \mathrm{h}$ in healthy subjects); hence, its use is not recommended for this group of patients. ${ }^{55}$ At present, there are no available data on the effects of exenatide administration in subjects with severe hepatic insufficiency. Exenatide is cleared primarily by the kidney; therefore, hepatic dysfunction is not expected to affect blood concentration of exenatide. ${ }^{37}$

\section{Drug Interactions}

The ability of exenatide to slow gastric emptying may reduce the extent and rate of absorption of orally administrated drugs. This fact should be taken into account when administering oral drugs that require rapid gastrointestinal absorption. For example, contraceptives and antibiotics, which are particularly dependent on threshold concentrations for efficacy, should be taken at least one hour before exenatide injection. ${ }^{37}$ Exenatide is not expected to have any clinically relevant effects on the pharmacokinetics of metformin or sulphonylureas. Hence, no restriction in the timing of the intake of these drugs in relation to exenatide injection is needed. ${ }^{37}$

Paracetamol was used as a model drug to evaluate the effect of exenatide on gastric emptying. In a drug interaction study, when $1,000 \mathrm{mg}$ paracetamol was given with $10 \mu \mathrm{g}$ exenatide at $0 \mathrm{~h},+1 \mathrm{~h},+2 \mathrm{~h}$ and $+4 h$, the maximum decrease of paracetamol area under the concentration-time curve (AUC) and maximum drug concentration $\left(C_{\max }\right)$ was observed between one and two hours post-exenatide administration. Paracetamol AUC, $C_{\max }$ and time to $C_{\max }\left(T_{\max }\right)$ were not significantly changed when paracetamol was given one hour before exenatide injection. Based on these study results, no adjustment to paracetamol dosing is required. ${ }^{37,50}$

Many patients with T2DM have dyslipidaemia, which requires treatment with three hydroxyl-3-methylglutaryl coenzyme (HMG COA) reductase inhibitors (statins). The potential interaction between exenatide and statins has been evaluated in two studies..$^{58}$ In an open-label, fixedsequence, clinical pharmacology study in which healthy subjects received $10 \mu \mathrm{g}$ twice daily (BID) of exenatide and lovastatin $(40 \mathrm{mg})$ or lovastatin

Exenatide is not expected to have

any clinically relevant effects on

the pharmacokinetics of metformin

or sulphonylureas. Hence, no

restriction in the timing of the intake

of these drugs in relation to exenatide

injection is needed.

(40mg) alone, lovastatin AUC and $C_{\max }$ were decreased by approximately $40 \%$ and $28 \%$, respectively, and $\mathrm{T}_{\max }$ was delayed by about four hours in the exenatide plus lovastatin group. In the 30-week placebo-controlled clinical trials, described in the clinical experience section, concomitant use of exenatide and HMG CoA reductase inhibitors was not associated with consistent changes in lipid profiles. Although no pre-determined dose adjustment is required, one should be aware of possible changes in low-density lipoprotein cholestrol (LDL-C) or total cholesterol. Lipid profiles should be monitored regularly. ${ }^{37}$

Exenatide has been also administered and studied in combination with digoxin, ${ }^{59}$ lisinopril and warfarin. A delay in $T_{\max }$ of about two hours was observed when digoxin, lisinopril or warfarin were administered 
Table 2: Adverse Events in the AMIGO Clinical Trials

\begin{tabular}{|c|c|c|c|c|c|c|c|c|c|}
\hline \multirow[t]{2}{*}{ Adverse Events } & \multicolumn{3}{|c|}{ +Metformin } & \multicolumn{3}{|c|}{ +Sulphonylureas } & \multicolumn{3}{|c|}{ +Sulphonylureas+Metformin } \\
\hline & Placebo & $5 \mu \mathrm{g}$ & $10 \mu \mathrm{g}$ & Placebo & $5 \mu \mathrm{g}$ & $10 \mu \mathrm{g}$ & Placebo & $5 \mu \mathrm{g}$ & $10 \mu \mathrm{g}$ \\
\hline Nausea & $23 \%$ & $36 \%$ & $45 \%$ & $7 \%$ & $39 \%$ & $51 \%$ & $20.6 \%$ & $39.2 \%$ & $48.5 \%$ \\
\hline Hypoglycaemia & $5 \%$ & $5 \%$ & $5 \%$ & $3 \%$ & $14 \%$ & $36 \%$ & $12.6 \%$ & $19.2 \%$ & $27.8 \%$ \\
\hline Diarrhoea & $8 \%$ & $12 \%$ & $16 \%$ & $4 \%$ & $11 \%$ & $9 \%$ & $6.5 \%$ & $10.2 \%$ & $17.4 \%$ \\
\hline$\overline{\text { URTI }}$ & $11 \%$ & $14 \%$ & $10 \%$ & & & & $19.4 \%$ & $11 ., 4 \%$ & $17.4 \%$ \\
\hline Vomiting & $4 \%$ & $11 \%$ & $12 \%$ & $2 \%$ & $10 \%$ & $13 \%$ & $4.5 \%$ & $14.7 \%$ & $13.7 \%$ \\
\hline Dizziness & $6 \%$ & $9 \%$ & $4 \%$ & $7 \%$ & $15 \%$ & $15 \%$ & 0 & 0 & 0 \\
\hline Sinusitis & $5 \%$ & $5 \%$ & $6 \%$ & 0 & 0 & 0 & 0 & 0 & 0 \\
\hline Feeling jittery & 0 & 0 & 0 & $2 \%$ & $12 \%$ & $15 \%$ & $6.9 \%$ & $8.6 \%$ & $11.6 \%$ \\
\hline Headache & 0 & 0 & 0 & $7 \%$ & $9 \%$ & $8 \%$ & $4.9 \%$ & $11 \%$ & $7.5 \%$ \\
\hline Serious treatment-emergent adverse events & $3.5 \%$ & $4.5 \%$ & $2.7 \%$ & $8 \%$ & $3 \%$ & $4 \%$ & $6 \%$ & $6 \%$ & $5 . \%$ \\
\hline
\end{tabular}

URTI = upper respiratory tract infection.

30 minutes after exenatide. No clinically relevant effects on $C_{\max }$ or AUC were observed. On the other hand, post-marketing reports in the US have described increases in international normalized ratio (INR) when exenatide and warfarin are used concomitantly. INR should be monitored closely during initiation and dose increase of exenatide therapy in patients on warfarin and/or cumarol derivatives. ${ }^{37}$

\section{Dosage and Administration}

Exenatide is a peptide and therefore cannot be administered orally. It has to be administrated via subcutaneous injection in the abdomen, thigh or upper arm at any time within the 60-minute period before the morning and evening meals. Exenatide should not be administered after a meal. If a dosage is missed, the treatment should be continued with the next regularly scheduled dosage. ${ }^{37}$ Exenatide treatment should be initiated at a dosage of $5 \mu \mathrm{g}$ administered BID for at least one month to improve tolerability. Then, the dosage may be increased to $10 \mu \mathrm{g}$ BID to further improve glycaemic control. Doses higher than $10 \mu \mathrm{g}$ BID are not recommended.

\section{Clinical Experience - Efficacy and Safety Studies}

The efficacy and safety of $5 \mu \mathrm{g}$ and $10 \mu \mathrm{g}$ exenatide administered BID have been evaluated in three phase III trials entitled: 'AC2993: Diabetes Management for Improving Glucose Outcomes' (AMIGO Studies). All studies were multicentre, randomised, triple-blind, placebo-controlled 30-week trials that enrolled more than 1,400 patients with T2DM. Study participants had inadequate glycaemic control with metformin, 60 sulphonylurea ${ }^{61}$ or a combination of both (at maximally effective doses). ${ }^{62}$

After the four-week placebo lead-in period, patients were randomly chosen for treatment with placebo, 5 or $10 \mu \mathrm{g}$ of exenatide BID. Patients in the $10 \mu \mathrm{g}$ exenatide group received $5 \mu \mathrm{g}$ of exenatide for the first four weeks of the study to mitigate the feeling of nausea. Placebo and exenatide were administered BID 15 minutes prior to breakfast and dinner by subcutaneous injection into the abdomen. ${ }^{60-62}$

The main efficacy end-point was the change in $\mathrm{HbA}_{1 \mathrm{C}}$ from baseline to week 30. Changes in fasting plasma glucose (FPG) and bodyweight and the percentage of subjects (baseline levels of $\mathrm{HbA}_{1 \mathrm{C}}>7 \%$ ) who achieved $\mathrm{HbA}_{1 \mathrm{C}}$ of $\leq 7 \%$ at week 30 were secondary measures. ${ }^{60-62}$ Table 1 presents the efficacy outcomes for exenatide in the phase III trials.

In the AMIGO studies, nausea was the most common adverse event with most episodes being mild to moderate, and progressive dose escalation lessened the incidence of exenatide-induced nausea. The dropout rate due to nausea varied between 1.8 and $4 \%$ in the exenatide-treated patients and was more frequent in the exenatide $10 \mu \mathrm{g}$ treatment groups. ${ }^{63}$ There was no increase in the incidence of hypoglycaemia in patients receiving exenatide in combination with metformin. ${ }^{60}$ The incidence of hypoglycaemia in relation to placebo was greater in patients treated with sulphonylureas, and was also dependent on the dose of suphonylurea. ${ }^{60-62}$

On the other hand, it is well-known that glucagon, growth hormone, cortisol and catecholamines are important counter-regulatory hormones that offer protection from hypoglycaemia. In a stepwise hypoglycaemic study, the potential effect of intravenous exenatide on counter-regulatory mechanisms to hypoglycaemia was evaluated. The results showed that

At week 30, patients taking exenatide who lost weight (from baseline $-2.1 \pm 0.2 \mathrm{~kg}$ ) continued to lose weight at week $82(-4.4 \pm 0.3 \mathrm{~kg})$. Post-prandial and fasting plasma glucose levels were also improved.

glucagon, growth hormone, adrenaline and cortisol levels were not affected or, in some cases (i.e. glucagon), were slightly increased during hypoglycaemia, indicating that the physiological counter-regulatory process is not affected by treatment with exenatide during hypoglycaemia. ${ }^{64}$ The most commonly reported adverse effects in the AMIGO studies are listed in Table 2.

In a 52-week, open-label extension of the AMIGO studies, 314 patients continued with their oral antidiabetic treatment and $10 \mu \mathrm{g}$ of exenatide $\mathrm{BID}$ (82 weeks of total drug exposure). ${ }^{65}$ Reduced $\mathrm{HbA}_{1 \mathrm{C}}$ levels observed at week $30(-0.9 \pm 0.1 \%$; mean $\pm \mathrm{SE})$ were maintained at week 82 $(-1.1 \pm 0.1 \%)$ with $48 \%$ of the patients attaining $\mathrm{HbA}_{1 \mathrm{C}} \leq 7 \%$. At week 30, patients taking exenatide who lost weight (from baseline $-2.1 \pm 0.2 \mathrm{~kg})$ continued to lose weight at week $82(-4.4 \pm 0.3 \mathrm{~kg})$. Postprandial and fasting plasma glucose levels were also improved. The most common adverse effects were similar to those observed in the AMIGO studies (nausea and hypoglycaemia) and tended to be mild to moderate in severity. Exenatide improved some CV risk factors such as high-density lipoprotein cholestrol (HDL-C), ${ }^{66}$ triglycerides and diastolic blood pressure 
(DBP), particularly in those patients who had the greatest bodyweight loss. Moreover, significant changes in lipid profiles were also observed in patients treated with exenatide who failed to lose a significant amount of weight. ${ }^{65}$ This may be of particular interest given that patients with T2DM have a two- to four-fold increased risk of suffering CV disease. ${ }^{67}$ Nevertheless, the impact on reduction of $\mathrm{CV}$ events associated with decreased $C V$ risk factors with exenatide treatment remains unknown. ${ }^{65}$

\section{Non-inferiority Studies with Insulin}

The efficacy and safety of exenatide compared with insulin glargine and biphasic insulin aspart 30/70 has been examined in three comparative, non-inferiority studies. ${ }^{68-70}$ In these studies, exenatide $5 \mu \mathrm{g}$ was administered BID for four weeks prior to administering $10 \mu \mathrm{g}$ for the rest of the study. Insulin glargine treatment was initiated at 10U/day, with subsequent adjustment according to fasting glucose using a

These preliminary data further support

a growing interest in the effects of

exenatide in the early stages of type 2

diabetes mellitus, with the aim of

examining whether or not it protects

$B$ cells and prevents the progression of

the disease.

pre-established algorithm. Insulin aspart was administered BID with dose modification depending on fasting glycaemia and post-prandial glycaemic levels two hours post-ingestion. In all three studies, exenatide was shown to be as effective as insulin glargine and insulin aspart in lowering mean $\mathrm{HbA}_{1 \mathrm{C}}$ (compared with baseline levels) in all treatment groups, and the percentage of individuals achieving $\mathrm{HbA}_{1 \mathrm{C}}$ was $7 \%$. In contrast, exenatide-treated patients lost between two and three kilograms, whereas insulin-treated subjects gained between 0.35 and $4 \mathrm{~kg}$ on average. In all studies, exenatide's safety profile was similar to that observed in the AMIGO studies previously described, and the most commonly reported adverse effect was mild or moderate nausea in approximately one-third of the patients. ${ }^{68-70}$

\section{Antiexenatide Antibodies}

Patients exposed to recommended doses of exenatide might produce antiexenatide antibodies during the first weeks of treatment. Consistent with the potentially immunogenic properties of protein and peptide pharmaceuticals, patients may develop antiexenatide antibodies following treatment with exenatide. In most patients who develop antibodies, antibody titres diminish over time. ${ }^{37}$

The patients who produced antiexenatide antibodies had similar rates and types of adverse events as those who did not. In the AMIGO clinical studies ( $n=963$ ), 38\% of patients showed low titres of antiexenatide antibodies at 30 weeks. ${ }^{60-62}$ Within this group, the glycaemic control level $\left(\mathrm{HbA}_{1 \mathrm{C}}\right)$ was generally comparable to that observed in those who did not produce antiexenatide antibodies. An additional $6 \%$ of patients had higher titres of antibodies at 30 weeks. In about half of these patients ( $3 \%$ of total patients who received exenatide in the controlled clinical studies), no response to exenatide treatment was observed.60-62 In two non-inferiority clinical studies of exenatide and insulin $(n=475)$, efficacy and adverse events were comparable in patients treated with exenatide regardless of antibody levels. 68,69

\section{Other Effects of Incretin Mimetics in the Course of Type 2 Diabetes Mellitus}

The function of $B$ cells progressively declines in T2DM, as has been observed in animal models. Muller et al. reported the existence of a deficit in $\beta$ - and $\alpha$-cell secretion in the islets of patients with T2DM.71 Exenatide has been shown to stimulate $B$-cell proliferation and islet neogenesis in stem cells both in vitro and in vivo. ${ }^{39}$ Different in vitro studies of exogenous administration of exenatide and GLP-1 provide evidence that exenatide might play an important role in maintaining B-cell mass and function and stimulating the proliferation and neogenesis of islet cells, as well as inhibiting cell apoptosis.72 Recent preliminary studies in patients who have undergone pancreatic islet transplants indicated that exenatide enhanced glycaemic response and $\mathrm{HbA}_{1 \mathrm{C}}$ levels. ${ }^{73-75}$ These observed effects may be due to the combination of several factors, such as its already known actions of slowed gastric emptying, enhanced glucagon suppression and improved B-cell function, as seen by the C-peptide levels recorded in these patients. Moreover, exenatide may also contribute to enhancing the first phase of insulin secretion, which is also decreased in this group of patients. Exenatide has been shown to restore the insulin secretion patterns, similar to those observed in subjects with no diabetes, both in the first (0-10 minutes) and second (10-180 minutes) phases of secretion. ${ }^{76}$

On the other hand, glucotoxicity and oxidative stress are two key factors in B-cell apoptosis in T2DM. Thiorexdoxin-interacting protein (TXNIP) has recently been described as a pro-apoptotic factor in $B$ cells and a potential mediator of glucotoxicity and oxidative stress. ${ }^{77}$ In an in vitro study, exenatide demonstrated that it inhibits oxidative stress-induced cell apoptosis and decreases TXNIP expression in pancreatic cells. ${ }^{77}$ These preliminary data further support a growing interest in the effects of exenatide in the early stages of T2DM, with the aim of examining whether or not it protects $B$ cells and prevents the progression of the disease. ${ }^{78}$ This new treatment approach based on the glucose-regulating effects of the incretin hormones (mimicking GLP-1 effects or prolonging the length of their action) should be the subject of more extensive clinical evaluation. The introduction of exenatide as the first-in-class drug of incretin mimetics provides physicians with a new and promising treatment option for T2DM.
1. American Diabetes Association. All About Diabetes. Available at: http://diabetes.org/diabetes-statistics/national-diabetes-factsheet.jsp (consulted 20 September, 2006).

2. World Health Organization. Diabetes Mellitus Fact Sheet 138. Available at:

http://www.who.int/mediacentre/factsheets/fs138/en/index.html (consulted 20 September 2006).

3. King H, Aubert RE, Herman WH, Global burden of diabetes, 1995-2025: prevalence, numerical estimates, and projections, Diabetes Care, 1998;21:1414-31.
4. Wild S, Roglic G, Green A, et al., Global prevalence of diabetes: estimates for the year 2000 and projections for 2030, Diabetes Care, 2004;27(5):1047-53.

5. Nathan DM, Buse JB, Davidson MB, et al., Management of hyperglycaemia in type 2 diabetes: a consensus algorithm for the initiation and adjustment of therapy. A consensus statement from the American Diabetes Association and the European Association for the Study of Diabetes, Diabetologia, 2006;49(8):1711-21.

6. United Kingdom Prospective Diabetes Study Group, Overview of
6 years' therapy of type 2 diabetes: a progressive disease, Diabetes, 1995;44:1249-58.

7. Moller, DE, New drug targets for type 2 diabetes and the metabolic syndrome, Nature, 2001;414:821-7.

8. Davidson MB, Bate G, Kirkpatrick P, Exenatide, Nat Review Drug Discov, 2005;4:713-14.

9. Elrick H, Stimmler L, Hlad CJ, Arai Y, Plasma insulin responses to oral and intravenous glucose administration, J Clin Endocrinol Metab, 1964;24:1076-82.

10. Mclntyre N, Holdsworth CD, Turner DS, Intestinal factors in the 
control of insulin secretion, J Clin Endocrinol Metab. 1965;25:1317-24.

11. Nauck MA, Homberger $E$, Siegel EG, et al., Incretin effects of increasing glucose loads in man calculated from venous insulin and C-peptide responses, I Clin Endocrinol Metab, 1986:63:492-8

12. Meier JJ, Gallwitz B, Askenas M, et al., Secretion of incretin hormones and the insulinotropic effect of gastric inhibitory polypeptide in women with a history of gestational diabetes, Diabetologia, 2005;48(9):1872-81.

13. Turton MD, O'Shea D, Gunn I, et al., A role for glucagonpeptide-1 in the central regulation of feeding, Nature, 1996;379:214.

14. Nauck MA, Holst JJ, Willms B, Schmiegel W, Glucagon-like peptide 1 (GLP-1) as a new therapeutic approach for type 2-diabetes, Exp Clin Endocrinol Diabetes, 1997;105:187-95

15. Drucker DJ, Minireview: the glucagon-like peptides, Endocrinology, 2001;142:521-7.

16. Kieffer TJ, Habener JF, The glucagon-like peptides, Endocrin Rev 1999:20:876-913.

17. Meier JJ, Nauck MA, Glucagon-like peptide-1 (GLP-1) in biology and pathology, Diabetes Metab Res Rev, 2005;21:91-117.

18. Gromada J, Broakc B, Schmitz O, Rorsman P, Glucagon-like peptide-1: regulation of insulin secretion and therapeutic potential, Basic Clin Pharmacol Toxicol, 2004:95:252-62.

19. Brubaker PL, Drucker DJ, Minireview: Glucagon-like peptides regulate cell proliferation and apoptosis in the pancreas, gut, and central nervous system, Endocrinology, 2004;145:2653-9.

20. Gromada J, Rorsman P, New insights into the regulation of glucagon secretion by glucagon-like peptide-1, Horm Metab Res, 2004;36:822-9.

21. Drucker DJ, Philippe J, Mojsov S, et al., Glucagon-like peptide stimulates insulin gene expression and increases cyclic AMP levels in a rat islet cell line, Proc Natl Acad Sci USA, 1987;84(10):3434-8.

22. Moens $K$, Heimberg $H$, Flamez $D$, et al., Expression and functional activity of glucagon, glucagon-like peptide 1 , and glucose-dependent insulinotropic peptide receptors in rat pancreatic islet cells, Diabetes, 1996:45(2):257-61.

23. MacDonald PE, El-Kholy W, Riedel MJ, et al., The multiple actions of GLP-1 on the process of glucose-stimulated insulin secretion, Diabetes, 2002;51(Suppl 3):S434-42.

24. Goke R, Wagner B, Fehmann HC, Goke B, Glucose dependenc of the insulin stimulatory effect of glucagon-like peptide- 1 (7-36) amide on the rat pancreas, Res Exp Med (Berl), 1993;193:97-103.

25. Quddusi S, Vahl TP, Hanson $K$, et al., Differential effects of acute and extended infusions of glucagon-like peptide-1 on first- and second-phase insulin secretion in diabetic and nondiabetic humans, Diabetes Care, 2003;26(3):791-8.

26. Nauck MA, Heimesaat MM, Orskov C, et al., Preserved incretin activity of glucagon-like peptide 1 [7-36 amide] but not of synthetic human gastric inhibitory polypeptide in patients with type-2 diabetes mellitus, J Clin Invest, 1993:91:301-7

27. Meier JJ, Nauck MA, Glucagon-like peptide 1(GLP-1) in biology and pathology, Diabetes Metab Res Rev, 2005,21(2):91-117.

28. Delgado-Aros S, Kim DY, Burton DD, et al., Effect of GLP-1 on gastric volume, emptying, maximum volume ingested, and postprandial symptoms in humans, Am J Physiol Gastrointest Liver Physiol, 2002:282(3):G424-31.

29. Willms B, Werner J, Holst JJ, et al., Gastric emptying, glucose responses, and insulin secretion after a liquid test meal: effects of exogenous glucagon-like peptide-1 (GLP-1)-(7-36) amide in type 2 (noninsulin-dependent) diabetic patients, J Clin Endocrinol Metab, 1996:81:327-32.

30. Schjoldager BT, Mortensen PE, Christiansen J, et al., GLP-1 (glucagon-like peptide 1) and truncated GLP-1, fragments of human proglucagon, inhibit gastric acid secretion in humans, Dig Dis Sci, 1989;34:703-8.

31. Tourrel C, Bailbe $D$, Lacorne $M$, et al., Persistent improvement of type 2 diabetes in the Goto-Kakizaki rat model by expansion of the beta-cell mass during the prediabetic period with glucagon-like peptide-1 or exendin-4, Diabetes, 2002;51(5): 1443-52.

32. Xu G, Kaneto H, Lopez-Avalos MD, et al., GLP-1/exendin-4 facilitates beta-cell neogenesis in rat and human pancreatic ducts, Diabetes Res Clin Pract, 2006;73(1):107-10.

33. Farilla L, Bulotta A, Hirshberg B, et al., Glucagon-like peptide inhibits cell apoptosis and improves glucose responsiveness of freshly isolated human islets, Endocrinology, 2003;144(12): 5149-58.

34. Zander M, Madsbad S, Madsen JL, Holst JJ, Effect of 6-week course of glucagon-like peptide 1 on glycaemic control, insulin sensitivity, and beta-cell function in type 2 diabetes: a parallelgroup study, Lancet, 2002;359(9309):824-30.

35. Drucker DJ, Minireview: the glucagon-like peptides, Endocrinology, 2001;142(2):521-7.

36. Holst JJ, Orskov C, Incretin hormones - an update, Scand I Clin Lab Invest, 2001;234:75-85.

37. Byetta: Summary of Product Characteristics. Available at: http://www.emea.europa.eu/htms/human/epar/a-fepar.htm (consulted 22 January 2007).

38. Fehmann HC, Jiang J, Schweinfurth J, et al., Stable expression of the rat GLP-I receptor in $\mathrm{CHO}$ cells: activation and binding characteristics utilizing GLP-I(7-36)-amide, oxyntomodulin, exendin-4, and exendin(9-39), Peptides, 1994;15(3):453-6.

39. Nielsen LL, Young AA, Parkes DG, Pharmacology of exenatide (synthetic exendin-4): a potential therapeutic for improved glycemic control of type 2 diabetes, Regul Pept, 2004;117(2): 77-88.

40. Nielsen LL, Baron AD, Pharmacology of exenatide (synthetic exendin-4) for the treatment of type 2 diabetes, Curr Opin Investig Drugs, 2003;4:401-5.

41. Bhavsar S, Lachappell R, Watkins J, Young A, Comparison of glucose lowering effects of exendin-4 and GLP-1 in db/db mice, Diabetes, 1998;47(Suppl 1):A192, abstract 0741.

42. Jodka C, Gedulin BR, Hoyt J, Exendin-4 potently regulates gastric emptying in rats, Diabetes, 1998;47:403A, abstract 1543.

43. Gedulin B, Jodka L, Hoyt J, Exendin-4 (AC2993) decreases glucagon secretion during hyperglycemic clamps in diabetic fatty Zucker rats, Diabetes, 1999;48:A199, abstract 0864.

44. Xu G, Stoffers DA, Habener JF, Bonner-Weir S, Exendin- 4 stimulates both beta-cell replication and neogenesis, resulting in increasing beta-cell mass and improved glucose tolerance in diabetic rats, Diabetes, 1999;48:2270-76.

45. Stoffers DA, Kieffer TJ, Hussain MA, et al., Insulinotropic glucagon-like peptide 1 agonists stimulate expression of homeodomain protein IDX-1 and increase islet size in mouse pancreas, Diabetes, 2000;49:741-8.

46. Szayna M, Doyle ME, Betkey JA, et al., Exendin-4 decelerates food intake, weight gain, and fat deposition in Zucker rats, Endocrinol, 2000;141:1936-41.

47. Parkes DG, Pittner R, Jodka C, et al., Insulinotropic actions of exendin-4 and glucagon-like peptide- 1 in vivo and in vitro, Metab Clin Exp, 2001;50:583-9.

48. Egan JM, Clocquet $A R$, Elahi $D$, The insulinotropic effect of acute exendin- 4 administered to humans: comparison of nondiabetic state to type 2 diabetes, I Clin Endocrinol Metab, 2002;87:1282-90

49. Li Y, Hansotia T, Yusta B, et al., Glucagon-like peptide-1 receptor signaling modulates beta cell apoptosis, J Biol Chem , 2003;278(1):471-8.

50. Blase E, Taylor K, Gao HY, et al., Pharmacokinetics of an oral drug (acetaminophen) administered at various times in relation to subcutaneous injection of exenatide (exendin-4) in healthy subjects, J Clin Pharmacol, 2005:45:570-77.

51. Calara F, Taylor K, Han J et al, A randomized, open-label, crossover study examining the effect of injection site on bioavailability of exenatide (synthetic exendin-4), Clin Ther, 2005;27:210-15

52. Kolterman OG, Buse JB, Fineman MS, et al., Synthetic exendin4 (exenatide) significantly reduces postprandial and fasting plasma glucose in subjects with type 2 diabetes, I Clin Endocrinol Metab, 2003:88:3082-9.

53. Kolterman $\mathrm{OG}$, Kim DD, Shen L, et al., Pharmacokinetics, pharmacodynamics, and safety of exenatide in patients with type 2 diabetes mellitus, Am I Health Syst Pharm, 2005;62:173-81.

54. Parkes D, Jodka C, Smith P, et al., Pharmacokinetic actions of exendin-4 in the rat: comparison with glucagon-like peptide-1, Drug Dev Res, 2001;53:260-67.

55. Jason L, Exenatide: An Incretin Mimetic for the Treatment of Type 2 Diabetes Mellitus, Clin Ther, 2006:28(5):652-65.

56. Linnebjerg $H$, Kothare $P$, Uenaka K, et al., Pharmacokinetics, pharmacodynamics, and tolerability of exenatide in Japanese patients with type 2 diabetes, Diabetic Medicine 2006;23(Suppl.4):534.

57. Linnebjerg $H$, Kothare $P$, Park S, et al., Exenatide pharmacokinetics in patients with mild to moderate renal dysfunction and end stage renal disease, Diabetes, 2005;54(Suppl.1):A116

58. Kothare PA, Linnebjerg $H$, Skrivanek Z, et al., Exenatide effects on statin pharmacokinetics and lipid response, Int I Clin Pharmacol Ther, 2007:4582:114-20.

59. Kothare PA, Soon DK, Linnebjerg $H$, et al., Effect of exenatide on the steady-state pharmacokinetics of digoxin, J Clin Pharmacol, 2005:45:1032-7.

60. Defronzo RA, Ratner RE, Han J, et al., Effects of exenatide (exendin-4) on glycemic control and weight over 30 weeks in metformin-treated patients with type 2 diabetes, Diabetes Care, 2005;28:1092-1100

61. Buse JB, Henry RR, Han J, et al., for the Exenatide-113 Clinical Study Group, Effects of exenatide (exendin-4) on glycemic control over 30 weeks in sulphonylurea-treated patients with type 2 diabetes, Diabetes Care, 2004;27:2628-35.

62. Kendall DM, Riddle MC, Rosenstock, J, et al., Effects of exenatide (exendin-4) on glycemic control over 30 weeks in patients with type 2 diabetes treated with metformin and a sulphonylurea, Diabetes Care, 2005;28:1083-91.

63. Fineman MS, Shen LZ, Taylor K, et al., Effectiveness of progressive dose-escalation of exentaide (exendin-4) in reducing dose-limiting side effects in subjects with type 2 diabetes, Diabetes Metab Res Rev, 2004;20:411-17.

64. Degn $K B$, Brock $B$, Juhl $C B$, et al., Effect of intravenous infusion of exenatide (synthetic exendin-4) on glucose-dependent insulin secretion and counterregulation during hypoglycemia, Diabetes, 2004;53:2397-403

65. Blonde L, Klein EJ, Han J, et al., Interim analysis of the effects of exenatide treatment on $\mathrm{A} 1 \mathrm{C}$, weight and cardiovascular risk factors over 82 weeks in 314 overweight patients with type 2 diabetes, Diab, Obes and Metabolism, 2006;8:436-47.

66. Kapitza C, Nauck M, Trautmann M, et al., Long-term treatment with exenatide was associated with improved post-prandial glycaemic control and a shift from small to large HLD and LDL particles, Diabetic Medicine, 2006;23(Suppl. 4):532.

67. Garber AJ, Attenuating CV risk factors in patients with diabetes: clinical evidence to clinical practice, Diabetes Obes Metab, 2002;4:S5-S12.

68. Heine RJ, Van Gaal LF, Johns D, et al., Exenatide versus insulin glargine in patients with suboptimally controlled type 2 diabetes, Ann Intern Med, 2005;143:559-69.

69. Trautmann ME, Burger J, Johns D, et al., A comparison of exenatide and insulin glargine in patients using a single oral antidiabetic agent [Abstract]. Presented at the 42nd European Association for the Study of Diabetes Annual Meeting: 14-17 September 2006. Copenhagen-Malmoe, Denmark-Sweden.

70. Nauck MA, Duran S, Kim D, et al., A comparison of twice-daily exenatide and biphasic insulin aspart in patients with type 2 diabetes who were suboptimally controlled with sulphonylurea and metformin: a non-inferiority study, Diabetologia, 2007;50(2):259-67.

71. Muller WA, Faloona GR, Aguilar-Parada E, Unger RH, Abnormal alpha-cell function in diabetes, Response to carbohydrate and protein ingestion, N Eng J Med, 1970;283(3):109-15.

72. Tütüncü 0 , Nathanson $D$, Sjöholm $A$, et al., Exendin-4 confers protection against apoptosis in human coronary artery endothelial cells, Diabetic Medicine, 2006;23 (Suppl. 4):673

73. Faradji RN, Froud T, Monroy K, et al., Metabolic effects of exenatide in post islet transplant recipients, World Transplant Congress 2006;342, Abstract 817.

74. Benedetti E, Martellato J, Wang Y, et al., Exenatide combined with islet transplantation for the treatment of type I diabetes, World Transplant Congress 2006, 339, Abstract 807.

75. Faradji R, Baidal DA, Cure $P$, et al., The use of exenatide to improve islet engraftment, function and long term survival, World Transplant Congress 2006, 342, Abstract 815.

76. Fehse F, Trautmann M, Holst JJ, et al., Exenatide augments first and second phase insulin secretion in response to intravenous glucose in subjects with type 2 diabetes, I Clin Endocrinol Metab, 2005;90(11):5991-7.

77. Minn AH, Hafele C, Shalev A, Thioredoxin-interacting protein is stimulated by glucose through a carbohydrate response element and induces beta-cell apoptosis, Endocrinology, 2005;146: 2397-405.

78. Chen J, Couto FM, Minn AH, Shalev A, Exenatide inhibits b-cell apoptosis by decreasing thioredoxin-interacting protein, Biochem Biophys Res Commun, 2006:346:1067-74. 